\title{
Trabalho em equipe
}

\author{
Geraldina Porto Witter \\ PUC-Campinas
}

Na escola atuam profissionais com a mesma fomação bem como com formação em áreas diversas do conhecimento. De fato, espera-se que cada vez mais se possa contar com uma equipe multidisciplinar para melhor atender às necessidades de desenvolvimento de todos os que nela estudam e trabalham.

Entretanto, trabalhar em equipe requer uma longa aprendizagem, uma perspectiva aberta para o que seja a educação, o processo ensino-aprendizagem e respeito ao outro. Os problemas são mais freqüentes em realidades carentes de caldo cultural científico, onde há preconceitos, imagens, atitudes preconcebidas e negativas em relação a temas, teorias, profissionais e falta formação para o trabalho inter e transdisciplinar.

A aprendizagem para o trabalho em equipe começa na pré-escola com o aprendizado do trabalho em cooperação, com adequada divisão de tarefas e responsabilidades, com o aprender a respeitar o outro. Deve prosseguir nos vários anos acadêmicos até a Universidade.

A Universidade deve formar o profissional de hoje para trabalhar tanto em equipe unidisciplinar como multidisciplinar. Para tanto, seja qual for a área profissional o elenco de disciplinas da graduação não apenas deve incluir matérias específicas como de área conexa e até mesmo mais distantes e genéricas. Na pós-graduação é que se espera maior especificidade de conteúdo mas mesmo aí cursar disciplinas optativas em programas ou áreas de concentração distintas deve facilitar, mais tarde, um trabalho interdisciplinar.

O programa de cada disciplina e a bibliografia utilizada devem cuidar e incluir em seus objetivos e especifidades itens que sirvam de base para uma atuação interdisciplinar e intradisciplinar com colegas de formação distinta, ou seja, que viabilizem alguma unificação.

Subjacentes aos aspectos já referidos está a aprendizagem de interação humana, de relações interpessoais produtivas. Certamente os estágios constituem cenários propícios para este rico aprendizado. Infelizmente, no Brasil eles tendem a ser unidisciplinares e mono teóricos, prejudicando a formação aqui discutida. Outro cenário universitário ótimo para ensinar a intra e inter disciplinaridade é a pesquisa quer entre docentes, quer envolvendo alunos de iniciação científica e de pós-graduação. Mas aqui também os esforços, no Brasil, tendem a ser esparsos e pouco estimulantes.

Os programas de extensão universitária além de ambiente propício à pesquisa interdisciplinar também deveriam oferecer treino sistemático para os alunos de como trabalhar cooperativamente em uma equipe multidisciplinar, ensinando-os a atuarem, a usar tecnologias, procedimentos, a desenvolver comportamentos compatíveis para o êxito do grupo.

Certamente, além da formação pessoal para atuar interdisciplinarmente há outras variáveis pessoais que não podem ser esquecidas tais como: motivação, personalidade, ética e liderança dos envolvidos. Além disso, há que serem consideradas as variáveis situacionais tais como a cultura vigente no trabalho, na escola, a arquitetura ambiental e entre outras.

O trabalho em equipe tanto pode ocorrer no exercício da prática profissional como da pesquisa, o preparo para atuação em uma, ou em outra, tem similaridades mas também tem espe- 
cificidades.

Hoje, o tema é tão relevante que não só se discute a interdisciplinaridade em termos de campo de trabalho e de estágio. A equipe e a própria interdisciplinaridade passaram a ser objeto de pesquisa. Aos poucos vem crescendo o conhecimento sobre a matéria, já se podendo arrolar os principais problemas e soluções. O Quadro 1 oferece uma série de itens que permitem ao leitor avaliar, ainda que genericamente como estão as condições de trabalho em equipes de que participa.

Se o leitor integra uma equipe, quer uni quer multidisciplinar, analise com o grupo quais problemas estão presentes na sua atuação. Encontrando o(s) problema(s) o grupo deve planejar estratégias que viabilizem alcançar soluções conforme e sugerido no Quadro I.

Caso haja dificuldade para auto-avaliação ou o grupo não consiga chegar cooperativamente a uma análise de consenso é conveniente buscar apoio externo para fazer a avaliação.

$\mathrm{Na}$ hipótese de estarem presentes no grupo, ainda que ocasionalmente, entre 10 e 11 problemas dificilmente se poderá considerá-la como realmente sendo um grupo fazendo um trabalho de equipe uni ou multidisciplinar. Se 12 ou mais problemas se fizerem presentes certamente não se trata de equipe cooperando na busca de solução de problemas educacionais e melhoria da qualidade da educação, são pessoas que trabalham paralelamente, no mesmo espaço e até enfocando as mesmas questões mas não formam uma equipe e a educação, as famílias, os alunos, o próprio grupo só tem a perder.

Caso não consigam se constituir como uma verdadeira equipe podem buscar apoio em especialistas externos que os ajudem a redirecionar seus trabalhos para alcançarem o status de equipe de profissionais-pesquisadores. Buscar este status é, certamente, assegurar progresso, melhorar a qualidade do ensinoaprendizagem, ampliar horizontes, viabilizar o desenvolvimento de todos e obter melhor qualidade de vida na e fora da escola.

Quadro I. Trabalho em equipe

\begin{tabular}{|c|c|}
\hline Problemas & Soluções \\
\hline $\begin{array}{l}\text { 1.lnexperiência em trabalho em gru } \\
\text { po. }\end{array}$ & $\begin{array}{l}\text { 1. Treinamento el ou assessoria para } \\
\text { trabalho em grupo }\end{array}$ \\
\hline $\begin{array}{l}\text { 2. Falta de definição de missão e de es- } \\
\text { trutura }\end{array}$ & $\begin{array}{l}\text { 2. Aprendizagem de definição de } \\
\text { metas. objetivo. missão e estabe. } \\
\text { lecimento de estrutura e tipo de } \\
\text { grupo. }\end{array}$ \\
\hline 3. Ausência de liderança facilitadora & $\begin{array}{l}\text { 3. Uso do modelo de tomada de decisão } \\
\text { em colaboração. }\end{array}$ \\
\hline 4. Influência desingual dos membros & $\begin{array}{l}\text { 4.Intercãmbio entre membros e } \\
\text { administração horizontal do grupo. }\end{array}$ \\
\hline $\begin{array}{l}\text { 5. Jargão e fronteiras; profissionais for- } \\
\text { tes e intolerantes }\end{array}$ & $\begin{array}{l}\text { 5. Desenvolvertolerãncia e busca de } \\
\text { consenso conceitual. de taxinomia } \\
\text { e de léxico. }\end{array}$ \\
\hline $\begin{array}{l}\text { 6. Decisão de cúpula e não de con- } \\
\text { senso }\end{array}$ & 6. Decisão em colaboração. \\
\hline $\begin{array}{l}\text { 7. Pouca colaboração ou forte com. } \\
\text { petição entre membros do grupo }\end{array}$ & $\begin{array}{l}\text { 7. Desenvolver esquemas motivacionais } \\
\text { para a cooperação e redução da }\end{array}$ \\
\hline
\end{tabular}




\begin{tabular}{|c|c|}
\hline & ição. \\
\hline $\begin{array}{l}\text { 8. Perspectivas pré concebidas e } \\
\text { preconceitos em relação a teorias. } \\
\text { disciplinas. sujeitos (crianças. } \\
\text { familia. etc.). }\end{array}$ & $\begin{array}{l}\text { 8. Discussão dos assuntos e propostas } \\
\text { por problema e não por disciplina } \\
\text { ou teoria. }\end{array}$ \\
\hline $\begin{array}{l}\text { 9. Falta de dados ecológicos. demogr.ífi. } \\
\text { cos. ete. }\end{array}$ & 9. Pesquisar em grupo. \\
\hline $\begin{array}{l}\text { 10. Dados contraditórios não resolvi- } \\
\text { dos. }\end{array}$ & $\begin{array}{l}\text { 10. Pesquisar e desenvolver tolerãncia } \\
\text { às discrepãncias. }\end{array}$ \\
\hline $\begin{array}{l}\text { 11. Pouco conhecimento sobre o pro. } \\
\text { blema. criança. famllia etc. }\end{array}$ & $\begin{array}{l}\text { 11. Pesquisar em grupo. buscar fontes. } \\
\text { discutir até consenso. }\end{array}$ \\
\hline 12. Desnível de fonnação da equipe & $\begin{array}{l}\text { 12. Membros mais capacitados devem } \\
\text { ajudar. sem predominar. os menos } \\
\text { competentes e estes devem buscar } \\
\text { fonnação em cursos especfticos } \\
\text { (especialização. mestrado. doutorado). }\end{array}$ \\
\hline 13. Falta de competência científica & $\begin{array}{l}\text { 13. Buscar assessoria a curto prazo } \\
\text { e a longo prazo buscar fonnação } \\
\text { específica. }\end{array}$ \\
\hline $\begin{array}{l}\text { 14. Dogmatismo e falta de atitudes } \\
\text { cientJ1icas }\end{array}$ & $\begin{array}{l}\text { 14. Tomada de decisão colaborativa } \\
\text { e fonnação científica. }\end{array}$ \\
\hline $\begin{array}{l}\text { 15. Falta de avaliação diagnóstica ou } \\
\text { avaliação do prisma de uma só dis- } \\
\text { ciplina }\end{array}$ & $\begin{array}{l}\text { 15. Instrumento de avaliação multi. } \\
\text { disciplinares e do uso comum aos } \\
\text { vários membros da equipe. }\end{array}$ \\
\hline $\begin{array}{l}\text { 16. Ênfase em diagnóstico (fim) e não } \\
\text { na programação }\end{array}$ & $\begin{array}{l}\text { 16. Diagnóstico como meio e ênface e mais } \\
\text { tempo e cuidados com a programação. }\end{array}$ \\
\hline $\begin{array}{l}\text { 17. Falta de avaliação de processo e } \\
\text { de programas }\end{array}$ & $\begin{array}{l}\text { 17- Fazer avaliações globais e especi- } \\
\text { ficas antes. duarante e após os } \\
\text { programas. }\end{array}$ \\
\hline $\begin{array}{l}\text { 18. Falta de uso dos dados das } \\
\text { pesquisas de avaliação }\end{array}$ & $\begin{array}{l}\text { 18. Aprender. valorizar e tomar uma } \\
\text { prãtica constante o uso dos dados } \\
\text { de pesquisas de avaliação. }\end{array}$ \\
\hline $\begin{array}{l}\text { 19. Avaliação de um ou poucos aspectos } \\
\text { ou do prisma de uma só disciplina }\end{array}$ & $\begin{array}{l}\text { 19. Avaliação de múltiplos aspectos e } \\
\text { multidisciplinar. }\end{array}$ \\
\hline $\begin{array}{l}\text { 20. Pseudo.participação de todos os } \\
\text { interessados (pais. administra. } \\
\text { dores etc.) }\end{array}$ & $\begin{array}{l}\text { 20. Valorizar e efetivar a participação } \\
\text { na equipe de membros ou de repre. } \\
\text { sentantes de todos os segmentos } \\
\text { da comunidade e das especialidades } \\
\text { constantes da equipe. }\end{array}$ \\
\hline $\begin{array}{l}\text { 21. Falta de relatórios e artigos apre- } \\
\text { sentados em congressos e publicados; } \\
\text { falta de democratização do conhe- } \\
\text { cimento }\end{array}$ & $\begin{array}{l}\text { 21. Melhorar a fonnação científica com } \\
\text { ênfase no papel do profissional } \\
\text { pesquisador e na publicação. }\end{array}$ \\
\hline 22. Ênfase em opiniões e "vivências" & $\begin{array}{l}\text { 22. Ênfase em dados. resultados de } \\
\text { pesquisa. em avaliações sistemáticas. }\end{array}$ \\
\hline
\end{tabular}


